\title{
Do medical students adhere to advice regarding a healthy lifestyle? A pilot study of BMI and some aspects of lifestyle in medical students in Poland
}

\author{
Dominika Kanikowska ${ }^{\mathrm{A}, C, D}$, Dorota Sikorska ${ }^{\mathrm{E}}$, Barbara Kuczyńska ${ }^{\mathrm{B}}$, Marian Grzymisławski ${ }^{\mathrm{E}}$, \\ Andrzej Bręborowicz, Janusz Witowski ${ }^{A, E, F}$ \\ Poznan University of Medical Sciences, Poland \\ A - research concept and design; $\mathrm{B}$ - collection and/or assembly of data; $\mathrm{C}$ - data analysis and interpretation; \\ $D$ - writing the article; $E$ - critical revision of the article; $F$ - final approval of the article
}

Address for correspondence

Dominika Kanikowska

E-mail:dkanikowska@ump.edu.pl

Funding sources

None declared

Conflict of interest

None declared

\section{Acknowledgments}

The authors wish to thank Professor J. Waterhouse (Liverpool John Moores University, UK) for his advice regarding the analysis of the results.

Received on March 2, 2016

Reviewed on September 16, 2016

Accepted on 0ctober 12, 2016

\begin{abstract}
Background. The components of lifestyle of medical students, with comprehensive reporting of their physical activity and drinking and eating behavior, are rarely evaluated. Being overweight (increased body mass index - BMI) is associated with health problems, an unhealthy lifestyle (inadequate sleep, diet and exercise) being implicated.
\end{abstract}

Objectives. The aim was to determine if there were discrepancies between assessments of actual lifestyle and advice regarding the principles of a healthy lifestyle.

Material and methods. The relationship between lifestyle and BMI was investigated in 270 medical students (158 females, 112 males) who answered a questionnaire about aspects of their lifestyle.

Results. The mean $\pm S D$ BMl in males $\left(23.41 \pm 0.25 \mathrm{~kg} / \mathrm{m}^{2}\right)$ was significantly higher than in females $\left(20.52 \pm 0.16 \mathrm{~kg} / \mathrm{m}^{2}\right)$. Many aspects of lifestyle differed significantly with gender, including sleep habits, number of meals eaten, types of food eaten (fast food, amounts of fresh fruit and vegetables, sweets, etc.) and alcohol consumption, males generally having less healthy lifestyles. After correcting the associations between BMI and lifestyle factors for gender, one main finding was a positive association between BMI and alcohol intake, BMl rising by $0.014 \mathrm{~kg} / \mathrm{m}^{2} / \mathrm{g}$ alcohol intake per week.

Conclusions. These results show clear differences between actual and advised lifestyle with regard to many aspects of sleep, food and fluid intake, and exercise. Most students, particularly males, had not adopted a healthy lifestyle. Possible future problems associated with this require more emphasis.

Key words: obesity, sleep, BMI, food intake

DOI

10.17219/acem/65783

Copyright

Copyright by Author(s)

This is an article distributed under the terms of the

Creative Commons Attribution Non-Commercial License

(http://creativecommons.org/licenses/by-nc-nd/4.o/) 


\section{Introduction}

Overweight or obesity is increasing in frequency in many countries, and is associated with several problems, including metabolic disorder and increased cardiovascular risk. ${ }^{1}$ Obesity occurs when energy intake exceeds its output for an extended period of time. The obvious causes of this imbalance are excessive food intake and/or inadequate physical activity, but other lifestyle factors poor diet and sleep hygiene - also exist; these have all been considered in detail. ${ }^{2,3}$ The present study elucidates the extent to which advice relating to healthy behavior (e.g., physical activity, eating appropriate food) is related to actual diet and physical activity among medical students. The main aim is to get individuals to develop a lifestyle which will prevent them from becoming overweight and obese, concentrating on medical students, who, in the future, will be health educators. With regard to the other lifestyle factors, sleep durations of less than normal length (defined in most studies as $\leq 6 \mathrm{~h}$ ) and sleep disorders have been connected with numerous metabolic changes. ${ }^{4-7}$ Epidemiological studies have shown that insufficient sleep may increase the risk of metabolic disturbances, including insulin resistance, obesity and type 2 diabetes. ${ }^{8,9}$ In addition, it has been argued that people whose sleep is shorter than normal have more time to eat and so increase their calorie intake by eating snacks or fast food, often high in fat, salt and carbohydrate content. ${ }^{10} \mathrm{~A}$ poor diet may also be one that contains too little roughage. ${ }^{11}$ The problems of obesity and the associated higher risks of metabolic and cardiovascular disorders that are found in adults can begin in childhood and be present in young adults. For example, body mass index (BMI) values indicative of being overweight or obese have been found in adolescent males aged 12-19 years, in 18-29-year-old college students and, when comparing BMI and weight gain, in individuals in the age ranges of 18-24 years and $25-30$ years. ${ }^{12-14}$

Advice to improve sleep hygiene and diet with the aim of reducing the likelihood of becoming overweight or obese is becoming important. ${ }^{15,16}$ Anti-obesity programs should be directed at children (or their guardians) and adolescents as well as adults, and the development of an effective program aimed at adolescents who are undergoing a critical period of weight gain might be particularly important. Directing such advice at young adults is also important because they are beginning to become independent, and so they need to develop a healthy lifestyle. For example, the Polish government offers some advice in this regard (National Health Programme 2007-2015). ${ }^{17}$

These are the reasons why the present pilot survey has focused on this stage of life. University students should form a good sample to investigate not only because they are becoming independent but also because they are old enough to be able to answer a questionnaire accurately (removing possible problems due to parents' mis-remembering or mis-reporting their child's habits, for example). ${ }^{18-20}$

The present study has examined sleep patterns, diet and physical activity among medical students at Poznan University (Poland), in order to establish if the aspects of lifestyle that might be associated with the early stages of becoming overweight or obese (as assessed by BMI) are present in young adults. It also seems reasonable to suppose that medical students are aware of the problems associated with being overweight and having a poor diet and poor sleep hygiene at least to the same extent as the population as a whole.

\section{Material and methods}

\section{Subjects}

Medical students who were attending Poznan Medical University between October 2012 and March 2013 were asked to take part in the survey. It was made clear that the participation was voluntary, and that not doing so or not completing the study would have no negative consequences upon the individual. Volunteers completed a consent form. The study was approved by the Ethics Committee of Poznan Medical University. A total of 270 students (158 females, 112 males), aged $19-32$ years (median $=21.0$ years) took part in the study. About $95 \%$ of them asked for a return of completed forms.

\section{Physical measurements}

A random sample of the volunteers was chosen, and it was confirmed that they had reported their height and weight (used to calculate BMI) accurately. BMI is defined as the individual's body mass divided by the square of their height $\left(\mathrm{kg} / \mathrm{m}^{2}\right) .{ }^{21}$ Overweight was defined as a BMI $>25$, and obesity as one of $\geq 30$. $^{22}$

\section{Questionnaire}

The volunteers then answered a questionnaire (45 questions) on their "recent habits" (based upon a typical day), with regard to sleep, food and fluid intake, and the amount of physical activity they had had. The questionnaire was in 3 parts and took about 15 minutes to answer: 1) general questions about their age, gender, height and weight; 2) questions about their sleep patterns; and 3) questions about their dietary habits and physical activity.

The questions relating to sleep patterns asked about typical times of retiring/rising and sleep length. Those about dietary habits regarded the frequencies of eating breakfast, a mid-morning snack, lunch, a mid-afternoon snack, dinner and supper. Questions were also asked about the weekly frequencies of eating fresh fruit 
or vegetables, sweets, salty foods, fast food and soft drinks; in no case was specific advice about the exact meaning of these groups given. Further questions asked about the volunteer's normal weekly intake of alcohol (beer, wine and spirits); the results were converted into a weekly consumption of alcohol (in grams). Finally, volunteers were asked how many times per week they were physically active, defining this as "engaged in moderate physical activity for at least $30 \mathrm{~min}$ ".

Table 1. Comparison of variables measured in males and females

\begin{tabular}{|c|c|c|c|c|}
\hline Topic & $\begin{array}{c}\text { Variable } \\
\text { (mean } \pm \text { SE) }\end{array}$ & $\begin{array}{c}\text { Females } \\
n=158\end{array}$ & $\begin{array}{l}\text { Males } \\
n=112\end{array}$ & p-value \\
\hline \multirow{3}{*}{ Sleep } & retiring time [decimal time] & $0.4 \pm 0.1$ & $0.3 \pm 0.1$ & ns \\
\hline & rising time [decimal time] & $7.1 \pm 0.1$ & $7.3 \pm 0.1$ & 0.056 \\
\hline & length of sleep [h] & $6.5 \pm 0.1$ & $6.9 \pm 0.1$ & 0.005 \\
\hline \multirow{7}{*}{ Food intake } & breakfast [times/day] & $0.92 \pm 0.02$ & $0.87 \pm 0.03$ & ns \\
\hline & elevenses [times/day] & $0.77 \pm 0.04$ & $0.59 \pm 0.05$ & 0.002 \\
\hline & lunch [times/day] & $0.97 \pm 0.01$ & $0.98 \pm 0.01$ & ns \\
\hline & tea [times/day] & $0.53 \pm 0.05$ & $0.38 \pm 0.05$ & 0.025 \\
\hline & dinner [times/day] & $0.91 \pm 0.03$ & $0.95 \pm 0.02$ & ns \\
\hline & supper [times/day] & $0.44 \pm 0.09$ & $0.47 \pm 0.04$ & ns \\
\hline & total meals [per day] & $4.35 \pm 0.08$ & $4.11 \pm 0.11$ & 0.067 \\
\hline \multirow{5}{*}{ Type of food } & vegetables/fruit [times/week] & $4.7 \pm 0.2$ & $3.8 \pm 0.2$ & 0.006 \\
\hline & sweet food [times/week] & $3.6 \pm 0.2$ & $2.6 \pm 0.2$ & $<0.001$ \\
\hline & salty food [times/week] & $1.05 \pm 0.1$ & $1.06 \pm 0.1$ & ns \\
\hline & fast food [times/week] & $0.5 \pm 0.1$ & $1.0 \pm 0.1$ & $<0.001$ \\
\hline & soft drins[times/week] & $0.8 \pm 0.1$ & $1.5 \pm 0.2$ & $<0.001$ \\
\hline Alcohol intake & alcohol intake [g/week] & $34 \pm 3$ & $66 \pm 5$ & $<0.001$ \\
\hline Exercise & physical activity [times/week] & $1.5 \pm 0.1$ & $2.6 \pm 0.2$ & $<0.001$ \\
\hline
\end{tabular}

ns - statistically non significant.

Table 2. Correlation of variables with BMI

\begin{tabular}{|c|c|c|c|}
\hline Topic & Variable of interest & $\begin{array}{l}\text { Pearson's correlation } \\
\text { coefficient, rs }\end{array}$ & $p$-value \\
\hline \multirow{3}{*}{ Sleep } & retiring time [decimal time] & 0.07 & ns \\
\hline & rising time [decimal time] & 0.069 & ns \\
\hline & length of sleep [h] & 0.157 & 0.01 \\
\hline \multirow{7}{*}{ Food intake } & breakfast [times/day] & 0.006 & ns \\
\hline & elevenses [times/day] & -0.146 & 0.05 \\
\hline & lunch [times/day] & 0.125 & 0.05 \\
\hline & tea [times/day] & -0.027 & ns \\
\hline & dinner [times/day] & 0.1 & ns \\
\hline & supper [times/day] & 0.049 & ns \\
\hline & total meals [number/day] & -0.012 & ns \\
\hline \multirow{5}{*}{ Type of food } & vegetables/fruit [times/week] & -0.054 & ns \\
\hline & sweet food [times/week] & -0.174 & 0.01 \\
\hline & salty food [times/week] & -0.011 & ns \\
\hline & fast food [times/week] & 0.189 & 0.01 \\
\hline & soft drins[times/week] & 0.13 & ns \\
\hline
\end{tabular}

\section{Statistics}

The results are presented as mean \pm SE, where $\mathrm{SE}$ is the standard error of the mean. The KolmogorovSmirnov test was used to show that the distributions did not deviate significantly from normal, allowing parametric statistical tests to be used. The equality of variances was checked with the Levene's test. Gender differences were assessed by t-tests, and the relationship between BMI and the other variables was analyzed with Pearson's correlation coefficient. Multivariate linear regression analysis was also used to assess predictors of BMI, always using gender (dichotomized as 1 = female, $2=$ male) as one predictor. Statistical calculations were performed using SPSS v. 17 (IBM, Armonk, USA). Significance was taken to be $\mathrm{p}<0.05$, and the results where $0.10>\mathrm{p}>0.05$ are described as "trends" or "marginally significant". Values given as " $\mathrm{p}=0.000$ " by the statistics package were recorded as " $\mathrm{p}<0.001$ ".

\section{Results}

A comparison between males and females in the variables measured is given in Table 1. The results of the correlation analysis are shown in Table 2, and of the regression analysis in Table 3.

\section{BMI}

The mean \pm SE BMI of the males $\left(23.41 \pm 0.25 \mathrm{~kg} / \mathrm{m}^{2}\right)$ was significantly higher than that of the females $\left(20.52 \pm 0.16 \mathrm{~kg} / \mathrm{m}^{2}\right)$ $(\mathrm{p}<0.001)$. The reliable and significant effect of gender upon BMI is also clearly shown in Table 3. Five females (3.1\%) and 26 males (23.2\%) had a BMI of $25 \mathrm{~kg} / \mathrm{m}^{2}$ or more (overweight or obese). Since there was a significant difference in BMI between males and females, this means that the interpretation of the effect of X upon BMI in the absence of this correction (Table 2) was ambiguous and that the interpretation of the effect of any factor X, upon BMI had to be corrected for this gender effect (Table 3).

\section{Sleep times}

Females retired at $0.4 \pm 0.1 \mathrm{~h}$ (decimal time; $00: 24 \mathrm{~h} \pm 6$ min by clock time), and males at $0.3 \pm 0.1 \mathrm{~h}(00: 18 \mathrm{~h} \pm 6 \mathrm{~min}$, clock time); this difference was not significant ( $\mathrm{p}=0.48)$. After taking into account any effects of gender, 
Table 3. Multivariate regression analysis including gender as one predictor

\begin{tabular}{|c|c|c|c|c|c|}
\hline \multicolumn{2}{|l|}{ Model for BMI } & \multicolumn{2}{|c|}{ Variable of interest } & \multicolumn{2}{|c|}{ Gender } \\
\hline $\begin{array}{l}\text { dependent: } \mathrm{BMI}\left[\mathrm{kg} / \mathrm{m}^{2}\right] \\
\text { independent: variable } \\
\text { of interest, gender } \\
\text { [1 = female, } 2 \text { = male] }\end{array}$ & $\begin{array}{l}p \text {-value for } \\
\text { the model }\end{array}$ & $p$-value & $\begin{array}{c}\text { beta } \\
\text { coefficient }\end{array}$ & p-value & $\begin{array}{c}\text { beta } \\
\text { coefficient }\end{array}$ \\
\hline Retiring time, gender & $<0.001$ & 0.071 & +0.223 & $<0.001$ & +2.92 \\
\hline Rising time, gender & $<0.001$ & ns & ns & $<0.001$ & +2.89 \\
\hline Length of sleep, gender & $<0.001$ & ns & ns & $<0.001$ & +2.89 \\
\hline Eating breakfast, gender & $<0.001$ & ns & ns & $<0.001$ & +2.91 \\
\hline Eating elevenses, gender & $<0.001$ & ns & ns & $<0.001$ & +2.83 \\
\hline Eating lunch, gender & $<0.001$ & 0.063 & +1.67 & $<0.001$ & +2.86 \\
\hline Eating tea, gender & $<0.001$ & ns & ns & $<0.001$ & +2.92 \\
\hline Eating dinner, gender & $<0.001$ & ns & ns & $<0.001$ & +2.86 \\
\hline Eating supper, gender & $<0.001$ & ns & ns & $<0.001$ & +2.88 \\
\hline Number of meals eaten, gender & $<0.001$ & ns & ns & $<0.001$ & +2.92 \\
\hline Vegetables/fruit eaten, gender & $<0.001$ & ns & ns & $<0.001$ & +2.94 \\
\hline Sweet food eaten, gender & $<0.001$ & ns & ns & $<0.001$ & +2.84 \\
\hline Salty food eaten, gender & $<0.001$ & 0.031 & -0.236 & $<0.001$ & +2.91 \\
\hline Fast food eaten, gender & $<0.001$ & ns & ns & $<0.001$ & +2.90 \\
\hline Soft drinks taken, gender & $<0.001$ & 0.046 & -0.192 & $<0.001$ & +3.04 \\
\hline Alcohol intake, gender* & $<0.001$ & 0.001 & +0.014 & $<0.001$ & +2.41 \\
\hline Physical activity, gender** & $<0.001$ & 0.007 & +0.194 & $<0.001$ & +2.66 \\
\hline
\end{tabular}

* The regression equation was built as follows: $\mathrm{BMI}=17.64+0.014 \times$ daily alcohol intake $+2.41 \times$ gender. The constant value was significant $(p<0.001)$; ** The regression equation was built as follows: $\mathrm{BMI}=17.55+0.194 \times$ physical activity $+2.66 \times$ gender. The constant value was significant $(p<0.001)$.

BMI tended to increase with later retiring times $(\mathrm{p}=0.071)$, increasing by $0.223 \mathrm{~kg} / \mathrm{m}^{2} / \mathrm{h}$. Males tended to rise later than females (7.3 $\pm 0.1 \mathrm{~h}$ vs $7.1 \pm 0.1 \mathrm{~h}$, decimal time; $\mathrm{p}=0.056)$ and sleep longer $(6.9 \pm 0.1 \mathrm{~h}$ vs $6.5 \pm 0.1 \mathrm{~h}$; $\mathrm{p}=0.005)$. However, when the effects of gender were incorporated into the regression analysis, BMI was not independently associated with either rising time or sleep length $(\mathrm{p}>0.05)$.

\section{Food intake}

When the meals (breakfast, mid-morning snack, lunch, mid-afternoon snack, dinner and supper) were considered individually, females ate a mid-morning and midafternoon snack more frequently than males $(0.77 \pm 0.04$ vs $0.59 \pm 0.05$ times/day; $\mathrm{p}=0.002$ and $0.53 \pm 0.05$ vs $0.38 \pm 0.05$ times/day; $\mathrm{p}=0.025$, respectively). These differences contributed to the observation that females tended to eat more meals per day than males $(4.35 \pm 0.08 \mathrm{vs}$ $4.11 \pm 0.11$ meals per day, $\mathrm{p}=0.067)$. However, the number of meals eaten per day did not exert a significant, independent influence on BMI. Only the frequency of eating lunch acted as a marginally significant $(\mathrm{p}=0.063)$ predictor of BMI when the effects of gender had been taken into account, BMI increasing by $1.67 \mathrm{~kg} / \mathrm{m}^{2} /$ daily frequency.

Females ate vegetables/fruit significantly more frequently (4.7 \pm 0.2 vs $3.8 \pm 0.2$ times/week; $\mathrm{p}=0.006$ ), sweets significantly more frequently $(3.6 \pm 0.2$ vs $2.6 \pm 0.2$ times/week; $\mathrm{p}<0.001)$, and fast food and soft drinks significantly less frequently $(0.5 \pm 0.1$ vs $1.0 \pm 0.1$ times/week; $\mathrm{p}<0.001$ and $0.8 \pm 0.1$ vs $1.5 \pm 0.2$ times/week; $\mathrm{p}=0.001$, respectively). Only the frequencies of eating salty food and drinking soft drinks significantly $(\mathrm{p}=0.031$ and $\mathrm{p}=0.046$, respectively) predicted BMI when gender had been taken into account, BMI decreasing by $0.236 \mathrm{~kg} / \mathrm{m}^{2} /$ daily frequency for salty food and by $0.192 \mathrm{~kg} / \mathrm{m}^{2} /$ daily frequency for soft drinks.

\section{Alcohol intake and activity}

Males drank significantly more alcohol than females $(66 \pm 5 \mathrm{~g} /$ week vs $34 \pm 3$ g/week, respectively; $\mathrm{p}<0.001$ ), and BMI was strongly and positively associated with alcohol intake when gender effects had been taken into account (a rise of $0.014 \mathrm{~kg} / \mathrm{m}^{2} / \mathrm{g}$ alcohol intake per week; $\mathrm{p}=0.001$ ). This result is shown in Table 3 and also illustrated in Fig. 1. This Figure shows that, on average, males drank more than females and also had a higher mean BMI, a result that has already been described. These results would be sufficient to account for a significant positive correlation between BMI and alcohol intake if gender was not taken into account. However, each gender independently showed a positive relationship between

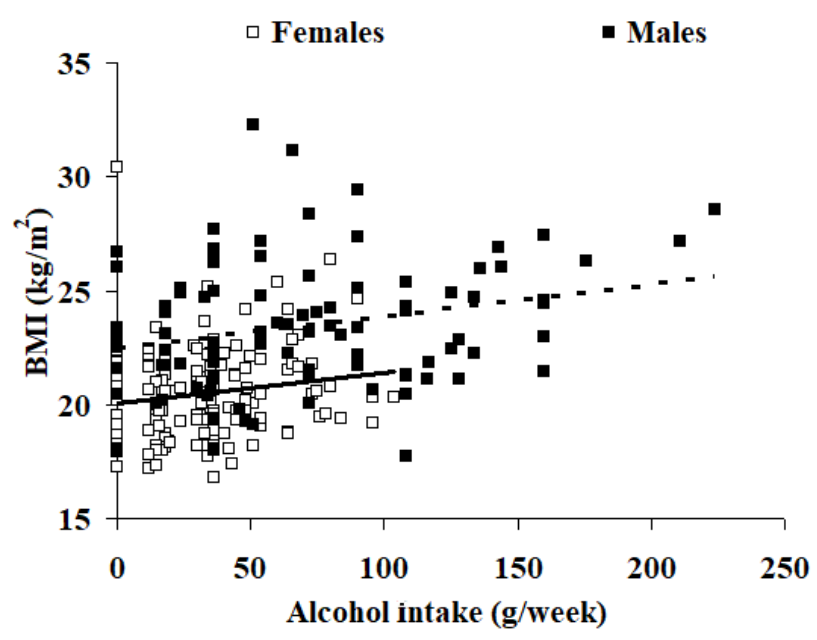

Fig. 1. Relationship between weekly intake of alcohol and BMI in males and females

Linear regression lines inserted: full line - females; dashed line - males. The regression equation is shown in Table 3. 
alcohol intake and BMI, as indicated by the regression lines both having slopes that are positive and significantly different from 0 .

It should be stressed that this finding, of a relationship between alcohol intake and BMI that is independent of gender effects, is in contrast with those for several other variables, discussed above, where no significant relationship between the variable and BMI was present if gender effects had been taken into account. Thus, for fast food intake, for example, males had higher mean values than females (see above and Table 1) and, coupling this finding with the fact that the males had a higher mean BMI, these results account for the significant positive correlation between fast food intake and BMI when gender had not been taken into account (Table 2); however, and by contrast with the results for alcohol, there was no significant relationship between fast food intake and BMI when gender had been taken into account (Table 3), indicating that the separate regression lines (of BMI upon fast food intake) for males and females had average slopes that did not differ significantly from 0 (data not illustrated).

Males were physically active more frequently than females $(2.6 \pm 0.2$ vs $1.5 \pm 0.1$ times per week, respectively; $\mathrm{p}<0.001$ ), and there was a significant, positive association between physical activity and BMI ( $\mathrm{p}=0.007$ ) after correction for any effect of gender, BMI rising by $0.194 \mathrm{~kg} / \mathrm{m}^{2} /$ occasion of physical activity.

\section{Discussion}

\section{BMI}

The results of this pilot study indicate that the sample of females had a significantly lower BMI than males, and this meant that investigations of the independent effect of another factor, X, upon BMI needed to be corrected for this gender effect. Previous studies have stressed the importance of taking gender into consideration when using BMI and measuring body fat/obesity in the population, or differences in physical activity, fitness and being overweight in adolescents. ${ }^{23,24}$ These results, which have been shown previously on many occasions, nevertheless indicate that the sample used was "normal". This can increase confidence when it comes to interpreting the new findings.

\section{Sleep hygiene}

Even though males tended to rise later and sleep significantly longer than females (Table 1), these variables did not exert an independent effect upon BMI (Table 3); only later retiring times had a marginal effect upon BMI when gender effects had been taken into account. Therefore, the present results provide only very limited support for the view that BMI is related to sleep hygiene. Earlier studies have examined the relationship between BMI and sleep, and have reported elevated risks of weight gain or obesity among persons with short sleep durations in both genders, particularly in women, or in men. ${ }^{7,25,26}$ By contrast, others have found no such association. ${ }^{27,28}$ The differences between the results of the studies might be due to the number of participants involved (studies failing to show any association tended to have smaller numbers). That is, it is possible that Type- 2 errors were present in smaller studies, and that they were under-powered with regard to demonstrating the relationship between BMI and sleep hygiene. Such an explanation might also apply to the lack of significant differences, or only a marginally significant difference, found in the present study. Resolving this issue requires an increased number of participants in a study or the performance of a metaanalysis of the published data.

\section{Food intake}

There were gender differences with regard to the frequency of eating some meals and the total number of meals eaten per day; females were more likely to eat mid-morning or mid-afternoon snacks than were males, and also tended to eat more meals per day. Eating patterns - choices involving when and where to eat, the types and amounts of foods eaten, and the circumstances leading to starting and stopping a meal or snack - can affect energy intake. ${ }^{29}$ Individuals have been divided into "grazers" and "gorgers". ${ }^{30}$ Grazers (those who eat small meals frequently throughout the day) may be at a metabolic advantage as compared to gorgers (who eat fewer, larger meals). Having fewer but larger meals may lead to increased obesity, possibly due to increased fat synthesis and storage following a large meal. ${ }^{31}$ These findings would offer some explanation for why the males in the present study had a higher BMI than the females, the males being more likely to overeat. However, there are few studies specifically examining the impact of meal frequency on body composition. One approach has investigated the metabolic effects of eating a single meal of known composition at different times of the day. The results indicate that a single meal taken in the morning is associated with a better control of body mass than the same meal taken later in the day. ${ }^{32}$ The detailed metabolic consequences of eating the same food at different times of day have still to be established, but possible differences include the amount of physical work performed during the daytime (less if there is no food intake until the evening) and endocrine responses to food intake (the insulin response to food intake being time-of-day dependent). ${ }^{33}$ Nevertheless, in the present study, BMI was not independently predicted by the frequency with which particular meals were eaten (with the possible exception of a marginal effect of the frequency of eating lunch), nor by the total number of meals eaten per day. The present results showed gender differences with regards to the type of food eaten. The females 
seemed to have a more healthy diet insofar as they ate more fresh vegetables/fruit and less fast food and soft drinks. An inverse association between vegetable and fruit intake and BMI was also found in the study by Heo et al. and in the study of Deliens et al., in which male students tended to increase their BMI more than female students. ${ }^{34,35}$ Heo et al. also found that vegetable and fruit intake was lower in individuals who were of lower socioeconomic status, current smokers or physically inactive. These aspects have not been investigated in the present study. ${ }^{34}$

\section{Alcohol intake and activity}

Gender differences were found (males drinking significantly more alcohol and performing significantly more physical activity each week) and there were also independent positive effects upon BMI of alcohol intake and the amount of physical activity performed.

These findings agree with those reported in the scientific literature. In the study by Di Milia et al., it was found that obesity was strongly associated with alcohol intake and low levels of physical activity. ${ }^{36}$ In a study of postmenopausal women, those who were of normal body weight and who reported only moderate alcohol intake had a reduced risk of becoming overweight or obese in the future compared with those who drank more heavily. ${ }^{37}$ In a study by Lahti-Koski et al., obesity was associated with alcohol consumption in both genders and BMI was inversely related to physical activity in women and to perceived health in men. ${ }^{38}$ In the European population, BMI was positively associated with frequent alcohol consumption and sedentary behavior. ${ }^{39}$

That is, an active lifestyle coupled with restricted alcohol intake has repeatedly been found to be associated with a lower BMI. Related to this, in the Dietary Guidelines for Americans, the recommended consumption of only up to 1 "standard" drink a day for women and up to 2 "standard" drinks a day for men emphasized moderation in alcohol intake (a "standard" drink being equal to 14.0 g of pure alcohol). ${ }^{40}$ "Heavy drinking" - more than 3 drinks on any day or more than 7 per week for women, and more than 4 drinks on any day or more than 14 per week for men - was associated with several health problems, including increased BMI levels indicative of being overweight or obese.

In summary, there is much evidence to indicate that high levels of alcohol intake lead to an increase of BMI, the observation in the present study that alcohol intake was positively associated with BMI, independent of gender differences, supporting this view. In the current sample, several participants, both males and females, drank rather more than the recommended levels; 3 females (who drank about $98 \mathrm{~g} /$ week) and 2 males (who drank more than $196 \mathrm{~g} /$ week) would be defined as "heavy drinkers". This habit might change when the students leave university, but it is important to advise them to reduce the amount they drink.
Increased physical activity was associated with increased BMI when gender effects had been taken into account. This result is in contrast to those reported by Di Milia et al., Lahti-Koski et al., and Stewart-Knox et al., where BMI decreased with the amount of physical activity. ${ }^{36,38,39}$ The explanation of our anomalous result might be that BMI reflects body mass, and this might be due to muscle rather than body fat. As a result, many athletes, for example, would be classified as "obese", even though their increased weight (for their height) is due to the development of muscle rather than an accumulation of excess body fat. This anomaly can only be resolved by making specific measurements of body fat (skinfold thickness or whole-body impedance, for example) rather than body mass, and it is recommended that such measurements be made in future studies.

\section{Implications of the results}

The present results enable areas where further work is needed to understand better the possible causal nexus that exists between lifestyle and BMI. This includes trying to ensure that any advice that is given is not only understood but also implemented by individuals in their daily lives. Even in this sample of highly educated young people, there is evidence that advice regarding their sleep hygiene and eating and drinking habits is not always being followed. Such advice needs to stress ways to keep BMI within recommended ranges and so reduce the risk of long-term effects associated with an increased BMI. Since in the present sample there were significant differences between females and males (females tending to live more healthy lifestyles with regard to sleep times and the intake of food and alcohol), it would appear that the need for such advice is greater in males. It has also been reported that males are less concerned about weight and a healthy lifestyle than women. ${ }^{41}$

Even though the results of the study showed only low prevalence of obesity and overweight amongst the students sampled, and even though health problems related to obesity and being overweight are more common in those who are middleaged and elderly, the study by Friedenberg et al. showed that BMI at the age of 18 was strongly predictive of obesity later in adulthood. ${ }^{42}$ Such findings stress that the provision of advice regarding these aspects of health promotion should be focused on young adults - university students, for example.

\section{Limitations and further work}

- In the present study, height, weight and sleep duration were self-reported by the subjects. Although selfreported weight and height are highly correlated with actual height and body weight, self-reported sleep duration correlates only moderately. ${ }^{43}$ People with sleep of short duration are more likely to over-report their sleep duration than are people with longer sleep durations; this may lead to a bias in the recorded values for sleep. ${ }^{44}$ 
- More detailed questions about sleep hours, waking activity and several aspects of food intake are required, particularly with regard to any differences that might exist between workdays and rest days. In addition, the results from questionnaires are always open to the criticism as they can be inaccurate. Keeping a daily diary of sleep and food/fluid intake during weekdays and weekends might reduce some of these problems.

- Obesity and overweight are better assessed by measuring skinfold thickness or whole-body impedance rather than calculating BMI from body height and mass, where ambiguities due to weight being due to muscle development or fat deposition exist. ${ }^{45}$

A new study in which at least some of these limitations are being addressed is currently under way.

\section{Conclusions}

The present study indicated that many students, particularly males, had not adopted a healthy lifestyle. These results highlight a gap between the knowledge that students have with regard to a healthy lifestyle and their practice on a daily basis.

BMI differed between the genders and there were several gender-based differences when rising time, length of sleep, frequency of eating some meals, and some types of food eaten were considered. In addition, independently of gender effects, BMI tended to be higher when individuals went to bed later, ate lunch more frequently, ate salty foods and drank soft drinks less often, and drank more alcohol. These findings concur with those of others and provide limited support for the view that BMI is adversely affected by poor sleep hygiene and eating habits. ${ }^{32,46}$

These results can provide a rationale for devising simple intervention measures aimed at preventing a rise in BMI and improving long-term health but they also show that any such advice is not being acted upon as seriously as it might be, at least with regard to medical students in Poland. Clearly, the results of the present study do not say if similar problems exist in other sections of the community in Poland, and whether the situation is similar in other countries. However, the epidemiological evidence (considered in the Introduction) points to the problems being widespread.

Nevertheless, one direct implication of the present findings is that the Polish Medical Association needs to advertise its recommendations more effectively, and more effort must be made to ensure that the recommendations are implemented. ${ }^{17}$

\section{References:}

1. World Health Organization (2013) WHO Fact sheet N311 - Obesity and overweight. WHO Media Centre [online database]. WHO: http:// www.who.int/topics/obesity/en/2013. Accessed December 15, 2015.
2. Boulos R, Vikre EK, Oppenheimer S, Chang H, Kanarek RB. Obesity: How television is influencing the obesity epidemic. Physiol Behav. 2012;107(1):146-153.

3. St-Onge MP, Roberts AL, Chen J, et al. Short sleep duration increases energy intakes but does not change energy expenditure in normal-weight individuals. Am J Clin Nutr. 2011;94(2):410-416.

4. Mullington JM, Chan JL, van Dongen HP, et al. Sleep loss reduces diurnal rhythm amplitude of leptin in healthy men. J Neuroendocrinol. 2003;15:851-854.

5. Spiegel K, Tasali E, Penev P, van Cauter E. Brief communication: Sleep curtailment in healthy young men is associated with decreased leptin levels, elevated ghrelin levels, and increased hunger and appetite. Ann Intern Med. 2004;141:846-850.

6. Sekine $M$, Yamagami $T$, Handa $K$, et al. A dose-response relationship between short sleeping hours and childhood obesity: Results of the Toyama Birth Cohort Study. Child Care Health Dev. 2002;28:163-170.

7. Xiao $\mathrm{Q}$, Arem H, Moore SC, Hollenbeck AR, Matthews CE. A large prospective investigation of sleep duration, weight change, and obesity in the NIH-AARP Diet and Health Study cohort. Am J Epidemiol. 2013;178(11):1600-1610.

8. Buxton OM, Marcelli E. Short and long sleep are positively associated with obesity, diabetes, hypertension, and cardiovascular disease among adults in the United States. Soc Sci Med. 2010;71:1027-1036.

9. Chao CY, Wu JS, Yang YC, et al. Sleep duration is a potential risk factor for newly diagnosed type 2 diabetes mellitus. Metabolism. 2011;60:799-804.

10. Chaput JP, Després JP, Bouchard C, Tremblay A. The association between short sleep duration and weight gain is dependent on disinhibited eating behavior in adults. Sleep. 2011;34(10):1291-1297.

11. Nedeltcheva AV, Kilkus JM, Imperial J, Kasza K, Schoeller DA, Penev PD. Sleep curtailment is accompanied by increased intake of calories from snacks. Am J Clin Nutr. 2009;89(1):126-133.

12. Ogden CL, Carroll MD, Kit BK, Flegal KM. Prevalence of obesity and trends in body mass index among US children and adolescents, 1999-2010. JAMA. 2012;307(5):483-490.

13. Mokdad AH, Serdula MK, Dietz WH, Bowman BA, Marks JS, Koplan JP. The spread of the obesity epidemic in the United States, 1991-1998. JAMA. 1999;282(16):1519-1522.

14. Burke GL, Bild DE, Hilner JE, Folsom AR, Wagenknecht LE, Sidney S. The spread of the obesity epidemic in the United States, 19911998. Differences in weight gain in relation to race, gender, age and education in young adults: The CARDIA Study. Coronary Artery Risk Development in Young Adults. Ethn Health. 1996;1(4):327-335.

15. Waterhouse J, Bailey L, Tomlinson F, Edwards B, Atkinson G, Reilly T. Food intake in healthy young adults: Effects of time pressure and social factors. Chronobiol Int. 2005;22:1069-1092.

16. Westerterp-Plantenga MS, Jedema MJ, Wijckmans-Duijsens NE. The role of macronutrient selection in determining patterns of food intake in obese and non-obese women. Eur J Clin Nutr. 1996;50:580-591.

17. Polish Ministry of Health: National Health Programme for the years 2007-2015. Annex to the Resolution of the Council of Ministers No. 90/2007 of 15 May 2007. www.mz.gov.pl/_data/ assets/.../1943_001pop.pdf. Accessed May 15, 2007.

18. Ko MS. The comparison in daily intake of nutrients, dietary habits and body composition of female college students by body mass index. Nutr Res Pract. 2007;1(2):131-142.

19. Sakamaki R, Amamoto R, Mochida Y, Shinfuku N, Toyama K. A comparative study of food habits and body shape perception of university students in Japan and Korea. Nutr J. 2005;4:31.

20. Sakamaki R, Toyama K, Amamoto R, Liu CJ, Shinfuku N. Nutritional knowledge, food habits and health attitude of Chinese university students: A cross sectional study. Nutr J. 2005;4:4.

21. World Health Organization (2006) Global database on body mass index (BMI). [online database]. http://www.who.int/bmi. Accessed April 17, 2008.

22. Kuczmarski RJ, Flegal KM. Criteria for definition of overweight in transition: Background and recommendations for the United States. Am J Clin Nutr. 2000;72(5):1074-1081.

23. Ranasinghe $C$, Gamage $P$, Katulanda P, Andraweera N, Thilakarathne S, Tharanga P. Relationship between body mass index (BMI) and body fat percentage, estimated by bioelectrical impedance, in a group of Sri Lankan adults: A cross sectional study. BMC Public Health. 2013;13(1):797. 
24. Trost SG, Pate RR, Sallis JF, et al. Age and gender differences in objectively measured physical activity in youth. Med Sci Sports Exerc. 2002;34(2):350-355.

25. Patel SR, Malhotra A, White DP, Gottlieb DJ, Hu FB. Association between reduced sleep and weight gain in women. Am J Epidemiol. 2006;164(10):947-954.

26. Itani O, Kaneita Y, Murata A, Yokoyama E, Ohida T. Association of onset of obesity with sleep duration and shift work among Japanese adults. Sleep Med. 2011;12(4):341-345.

27. Appelhans BM, Janssen I, Cursio JF, et al. Sleep duration and weight change in midlife women: The SWAN sleep study. Obesity (Silver Spring). 2013;21(1):77-84.

28. Stranges S, Cappuccio FP, Kandala NB, et al. Cross-sectional versus prospective associations of sleep duration with changes in relative weight and body fat distribution: The Whitehall II Study. Am J Epidemiol. 2008;167(3):321-329.

29. Blundell JE, Cooling J. Routes to obesity. Phenotypes, food choices and activity. Br J Nutr. 2000;83(Suppl 1):33-38.

30. de Castro JM. When, how much and what foods are eaten are related to total daily food intake. Br J Nutr. 2009;102:1228-1237.

31. Verboeket-van de Venne WP, Westerterp KR. Influence of the feeding frequency on nutrient utilization in man: Consequences for energy metabolism. Eur J Clin Nutr. 1991;45(3):161-169.

32. Keim N, VanLoan M, Horn W, Barbieri T, Mayclin P. Weight loss is greater with consumption of large morning meals and fat-free mass is preserved with large evening meals in women on a controlled weight reduction regimen. J Nutr. 1997;127:75-82.

33. Bray MS, Tsai JY, Villegas-Montoya C, et al. Time-of-day-dependent dietary fat consumption influences multiple cardiometabolic syndrome parameters in mice. Int J Obes (Lond). 2010;34(11):1589-1598.

34. Heo M, Kim RS, Wylie-Rosett J, Allison DB, Heymsfield SB, Faith MS. Inverse association between fruit and vegetable intake and BMI even after controlling for demographic, socioeconomic and lifestyle factors. Obesity Facts. 2011;4(6):449-455.

35. Deliens T, Clarys P, van Hecke L, de Bourdeaudhuij I, Deforche B. Changes in weight and body composition during the first semester at university: A prospective explanatory study. Appetite. 2013;65:111-116.
36. Di Milia L, Vandelanotte C, Duncan MJ. The association between short sleep and obesity after controlling for demographic, lifestyle, work and health related factors. Sleep Med. 2013;14(4):319-323.

37. Thomson CA, Wertheim BC, Hingle M, et al. Alcohol consumption and body weight change in postmenopausal women: Results from the Women's Health Initiative. Int J Obes (Lond). 2012;36(9):1158-1164.

38. Lahti-Koski M, Pietinen P, Heliövaara M, Vartiainen E. Associations of body mass index and obesity with physical activity, food choices, alcohol intake, and smoking in the 1982-1997 FINRISK Studies. Am J Clin Nutr. 2002;75(5):809-817.

39. Stewart-Knox B, Duffy ME, Bunting B, Parr H, vas de Almeida MD, Gibney M. Associations between obesity (BMI and waist circumference) and socio-demographic factors, physical activity, dietary habits, life events, resilience, mood, perceived stress and hopelessness in healthy older Europeans. BMC Public Health. 2012;12:424.

40. U.S. Department of Agriculture and U.S. Department of Health and Human Services. Dietary guidelines for Americans, 2010. $7^{\text {th }}$ ed. Washington, DC: U.S. Government Printing Office; 2010.

41. Cluskey M, Grobe D. College weight gain and behavior transitions: Male and female differences. J Am Diet Assoc. 2009;109(2):325-329.

42. Friedenberg FK, Tang DM, Vanar V, Mendonca T. Predictive value of body mass index at age 18 on adulthood obesity: Results of a prospective survey of an urban population. Am J Med Sci. 2011;342(5):371-382.

43. Stevens J, Keil JE, Waid LR, Gazes PC. Accuracy of current, 4-year, and 28-year self-reported body weight in an elderly population. Am J Epidemiol. 1990;132(6):1156-1163.

44. Lauderdale DS, Knutson KL, Yan LL, Liu K, Rathouz PJ. Self-reported and measured sleep duration: How similar are they? Epidemiology. 2008;19(6):838-845.

45. Vìtrovská R, Vilikus Z, Klaschka J, et al. Does impedance measure a functional state of the body fat? Physiol Res. 2014;63(Suppl 2): 309-320.

46. Baron KG, Reid KJ, Kern AS, Zee PC. Role of sleep timing in caloric intake and BMI. Obesity (Silver Spring). 2011;19(7):1374-1381. 